\title{
A rare case of triple parathyroid adenoma with hyperparathyroidism occuring at a young age
}

GÜZIDE GONCA ÖRÜK*, MEHMET HACIYANLI ** , MELIKE BEDEL KORUYUCU ${ }^{* * *}$, EBRU RÜKŞEN ****, ÖZLEM GÜR, ${ }^{* *}$ CENGIZ TAVUSBAY **. HÜSNÜ YILMAZ *, BARIS ÖNDER PAMUK *

İzmir Katip Çelebi University, Atatürk Training and Research Hospital, Departments of Endocrinology ${ }^{*}$, Surgery ${ }^{\star *}$, Radiodiagnostics ${ }^{\star \star *}$, Nuclear Medicine $^{\star \star \star \star}$

\section{OBJECTIVES}

Lesions causing primary hyperparathyroidism (PHP) can be summarized as solitary adenoma (80-85\%), multiglandular hyperplasia $(15 \%)$, parathyroid carcinoma $(1 \%)$. While double adenomas are identified in $2-15 \%$ of the patients which are operated for PHP, triple adenomas are very rare $(1,2)$.

\section{METHODS}

The case is presented because in the recent years patients who are admitted to the hospital with intense bone complaints are very unusual and multiple adenomas are also seldom. 22 years old female patient was admitted to orthopedics outpatient clinic with symptoms of inability to walk and severe pain with actitvity and mass at proximal area of left femur. The patient was evaluated wtih biochemistry, thyroid doppler ultrasonography , $20 \mathrm{mCi}$ Tc-99m MIBI SPECT.

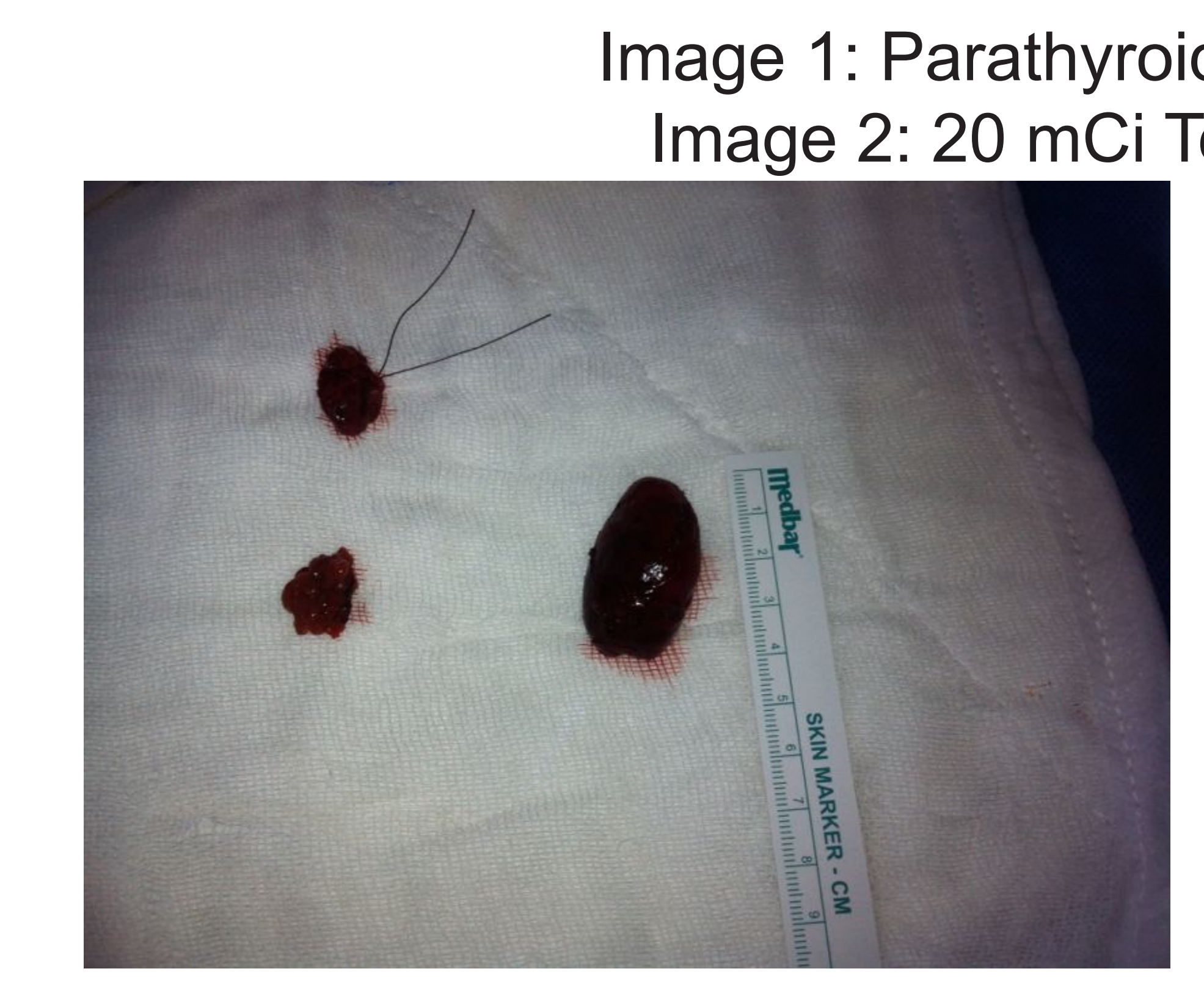

Table 1: Laboratuary values before and after surgery

\begin{tabular}{|l|l|l|}
\hline & Before surgery & After surgery \\
\hline Calcium $(\mathrm{mg} / \mathrm{dl})$ & 11.8 & 8.4 \\
\hline Phosphorus $(\mathrm{mg} / \mathrm{dl})$ & 2.2 & 3.6 \\
\hline PTH $(\mathrm{pg} / \mathrm{ml})$ & 2754 & 10 \\
\hline ALP (U/L) & 1275 & 892 \\
\hline 24 hour urine calcium & 288 & 280 \\
\hline BUN (mg/dl) & 5 & 4 \\
\hline Creatinine $(\mathrm{mg} / \mathrm{dl})$ & 0.41 & 0.4 \\
\hline
\end{tabular}

\section{CONCLUSIONS}

Usually PHP is expected to occur at later stages of life, but PHP should also be kept in mind in patients with serious bone complaints, high calcium and PTH levels. Early diagnosis and appropriate treatment can be prevent morbidity and mortality related with PHP.

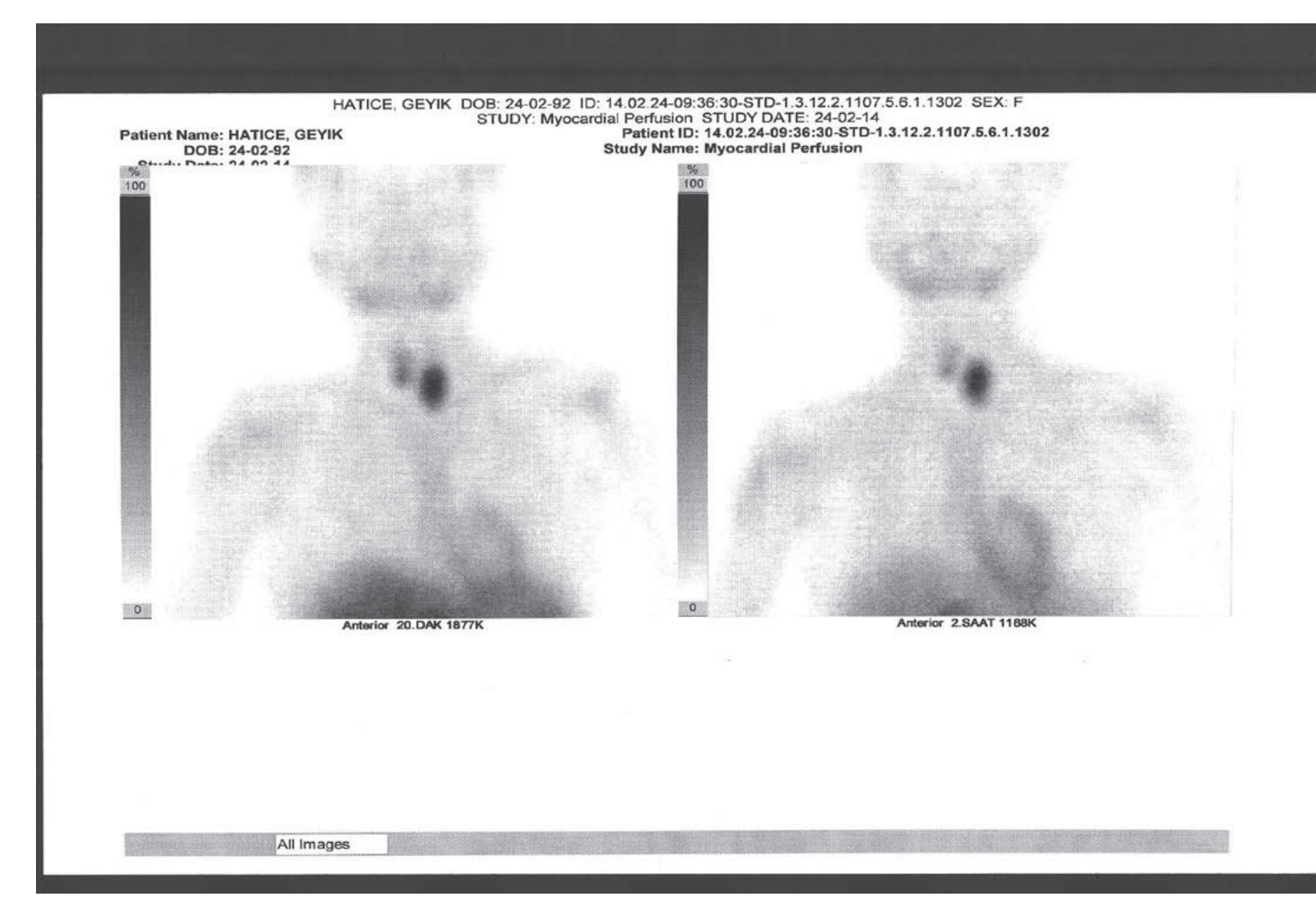

evaluation calcium and parathyroid hormone $(\mathrm{PTH})$ levels were discovered to be high. Calcium : $11.8 \mathrm{mgdl}$, phosphorus: 2.2 mgdl, alkaline phosphotase (ALP): $1275 \mathrm{U} / \mathrm{L}, \mathrm{PTH}: 2754 \mathrm{pg} / \mathrm{ml}, 24$ hour urine calcium: $288 \mathrm{mg} / \mathrm{day}, \mathrm{BUN}: 5 \mathrm{mg} / \mathrm{dl}$, creatinine: 0.41 $\mathrm{mg} / \mathrm{dl}, 25(\mathrm{OH})$ D Vitamin: $3.2 \mu \mathrm{g} / \mathrm{l}$ Thyroid doppler

ultrasonography revealed a $20 \times 17 \times 7 \mathrm{~mm}$ mass at the right lobe of the thyroid and at the caudal region of this lesion a $13 \times 11 \times 9$ $\mathrm{mm}$ mass, also a $36 \times 22 \times 23 \mathrm{~mm}$ lesion at the left lobe of the thyroid continuing to the mediastinum consistent with right and left-sided parathyroid adenomas. $20 \mathrm{mCi}$ Tc-99m MIBI SPECT images demonstrated hyperdense activity only at the left side (Image 2). Before the operation the patient was screened for multiple endocrine neoplasia because of her young age, results were negative. After the operation three parathyroid adenomas were discovered (Image 1) and PTH and calcium levels regressed to $10 \mathrm{pg} / \mathrm{ml}$ and $8.4 \mathrm{mg} / \mathrm{dl}$ respectively (Table 1 ).

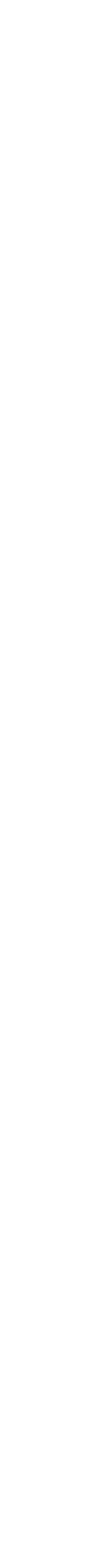

